\title{
Mudanças na organização escolar e formação docente continuada em um município do interior paulista
}

\author{
Changes in school organization and teachers' continuing education in a city of São Paulo state
}

Cambios en la organización escolar y la formación continua del profesorado en una ciudad del interior de São Paulo

Vanessa Moraes Abdala Guarda - Prefeitura do Município de Piracicaba | Rede Municipal de Educação de Piracicaba | Piracicaba | SP | Brasil. Contato: vaneabdala@yahoo.com.br | (10) orci

Andreza Barbosa - Universidade de Sorocaba - Uniso | Programa de Pós-Graduação em Educação | Sorocaba | SP | Brasil. E-mail: andrezab27@gmail.com | (1) овсі

Renata Cristina Oliveira Barrichelo Cunha - Centro Universitário Salesiano de São Paulo / Programa de Pós-Graduação em Educação / Americana / SP / Brasil. E-mail: renata_bcunha@yahoo.com.br | (1) orciD

Resumo: $\mathrm{O}$ artigo problematiza as ações de formação docente continuada de uma rede municipal de educação no cenário das reformas educacionais implementadas no Brasil a partir dos anos 1990 que acabaram por alterar profundamente a organização escolar. Com base em pesquisa que buscou compreender como são desenvolvidas as ações de formação continuada nas escolas municipais de ensino fundamental de um município do interior paulista, destaca-se que a organização escolar vem sendo modificada por meio de reformas pensadas de forma externa à escola e que modificam o currículo que se pratica em sala de aula, as metodologias, os processos de avaliação e que têm na formação docente um elemento estratégico para promover essas mudanças. Neste sentido, destaca-se na pesquisa a centralidade que a formação promovida pelo Programa Ler e Escrever assumiu no cotidiano das escolas da rede em questão, modificando toda a sua organização, constituindo-se como instrumento de padronização do trabalho docente.

Palavras-chave: Formação continuada. Organização escolar. Trabalho docente.

Abstract: This article discusses about the actions of teachers' continuing education in a city of São Paulo state in the context of educational reforms implemented in Brazil since the 1990s, that profoundly changed the school eorganization. Based on research that sought to understand how continuing education actions are developed in elementary schools in this city, it is highlighted that the school organization has been modified through reforms thought outside the school and that modify the curriculum that is practiced in the classroom, the methodologies, the assessment processes and that have a strategic element in teacher education to promote these changes. In this way, the research highlights the centrality that the training promoted by the Program Ler e Escrever has assumed in the daily lives of the schools in the searched system, changing its entire organization, constituting itself as a standard instrument for teachers' work.

Keywords: Continuing education. School organization. Teachers' work. 
GUARDA, Vanessa Moraes Abdala; BARBOSA, Andreza; CUNHA, Renata Cristina Oliveira Barrichelo. Mudanças na organização escolar e formação docente continuada em um município do interior paulista.

Resumen: El artículo analiza las acciones de la formación continua de docentes en una red de educación municipal en el contexto de las reformas educativas implementadas en Brasil desde la década de 1990, que cambiaron profundamente la organización escolar. Con base en una investigación que buscaba entender cómo se desarrollan las acciones de educación continua en las escuelas primarias de un municipio del interior de São Paulo, se destaca que la organización escolar ha sido modificada a través de reformas pensadas fuera de la escuela y que modifican el currículo que se practica, las metodologías, los procesos de evaluación y que tienen un elemento estratégico en la formación docente para promover estos cambios. En este sentido, se destaca en la investigación la centralidad que la capacitación promovida por el Programa Ler e Escrever asumió en el cotidiano de las escuelas en la red en cuestión, cambiando toda su organización, constituyéndose como un instrumento para la estandarización del trabajo docente.

Palabras clave: Formación continua. Organización escolar. Trabajo docente. 


\section{Introdução}

A década de 1990 marca um período ímpar no Brasil no que se refere às reformas no Estado e, consequentemente, nas políticas públicas. Tais reformas tiveram início nos anos de 1980 e intensificaram-se na década seguinte, marcando fortemente a redução nas atribuições clássicas do Estado. Com isso, as reformas no âmbito educacional também se intensificaram e a educação passou a ter maior centralidade nas decisões políticas, sofrendo a influência do Banco Mundial, da Organização das Nações Unidas para a Educação, a Ciência e a Cultura (UNESCO) e do Fundo das Nações Unidas para a Infância (UNICEF), organismos internacionais que financiam e definem as diretrizes que orientam políticas e projetos educacionais em diferentes países do mundo (TORRES, 1996; SANTOS, 2004).

O conjunto de reformas implementado impôs-se de forma verticalizada e foi organizado sem a participação dos professores, cabendo a esses a execução das ações planejadas nas esferas centrais e, também, a busca de meios para alcançar o sucesso das mudanças implementadas.

No geral, essas reformas foram pautadas por orientações referenciadas pela lógica gerencialista, fundamentando-se em modelos baseados na flexibilidade administrativa e apoiados em uma suposta busca de melhoria da qualidade na educação. A concepção de qualidade defendida pelo ideário reformista compreende-a como um dado mensurável e quantificável estatisticamente, a qual poderia ser alcançada a partir de inovações na organização e na gestão do trabalho desenvolvido na escola (OLIVEIRA, 2010).

A formação dos professores, sobretudo a formação continuada, assume papel importante nesse cenário. Em função disso, este trabalho, decorrente de pesquisa desenvolvida em um curso de mestrado em educação, problematiza, a partir do olhar de professoras e coordenadoras pedagógicas, como são desenvolvidas as ações de formação continuada nas escolas municipais de ensino fundamental de um município do interior paulista.

Importante destacar que a formação continuada se refere, como apontado por Cunha (2013, p. 4), a “[...] iniciativas instituídas no período que acompanha o tempo profissional dos professores" e podem ter formatos e tempos de duração diferenciados, tendo origem na própria iniciativa dos professores como estar inseridas em programas institucionais de escolas, redes de ensino, universidades ou outras agências. 
Na concepção adotada neste trabalho, a formação continuada tem como compromissos “[...] fomentar o desenvolvimento pessoal, profissional e institucional do professorado, potencializando um trabalho colaborativo" (IMBERNÓN, 2009, p. 49).

As informações levantadas por meio de entrevistas realizadas junto a professoras e coordenadoras pedagógicas apontaram que, com as reformas educacionais implementadas, a organização escolar foi alterada expressivamente, tendo sido impostas novas formas e conteúdos a serem ensinados, trazendo novas exigências para os profissionais da educação e modificando significativamente o trabalho docente.

\section{As reformas educacionais a partir da década de 1990 e as mudanças na organização escolar}

Segundo Oliveira (2010), as reformas educacionais implementadas no Brasil nos anos 1990 alteraram significativamente não só a organização do trabalho na escola, como também a própria organização escolar.

Os princípios definidos na Conferência Mundial sobre Educação para Todos, realizada em Jomtien no ano de 1990, inicialmente voltados à ampliação do atendimento educacional e à redução das desigualdades sociais, serviram de orientação para as reformas educacionais dos países mais pobres e populosos do mundo. Neste sentido, Oliveira (2004) faz um importante apontamento, no qual, para a autora:

Observa-se, então, um duplo enfoque nas reformas educacionais que se implantam nesse período na América Latina: a educação dirigida à formação para o trabalho e a educação orientada para a gestão ou disciplina da pobreza. A fórmula para se expandirem os sistemas de ensino de países populosos e com grandes níveis de desigualdade social será buscada por meio de estratégias de gestão e financiamento, que vão desde a focalização das políticas públicas educacionais ao apelo ao voluntarismo e ao comunitarismo (p. 1131).

Embora tenham se intensificado nos anos 1990, de acordo com Fernandes (2008), as reformas educacionais iniciam-se já nos anos de 1980 com a abertura política e a implantação de mecanismos que tinham como objetivo favorecer a participação popular e a democratização das decisões e das relações de trabalho, o que trouxe à discussão temas como democratização do ensino, superação do fracasso escolar, maior autonomia das escolas, trabalho coletivo, gestão democrática e inclusão social. 
Como defendido por Oliveira (2010), com a redução do papel do Estado na manutenção das políticas sociais promovida pelas reformas, a educação passa a ser considerada no âmbito das Condições Gerais de Produção (MARX, 2013) ${ }^{1}$, sendo indispensável para a plena realização da produção capitalista.

Nesta perspectiva, destacam-se as orientações de organismos internacionais, sobretudo do Banco Mundial, como o currículo baseado nas demandas do mercado, a ênfase dada à educação básica, a redução de gastos com o ensino superior, a ênfase na avaliação do ensino como produto e como controle, a centralidade da formação docente em serviço em detrimento da formação inicial, maior autonomia das escolas, o maior envolvimento das famílias no processo educativo, o desenvolvimento de políticas compensatórias com vistas a atender os portadores de deficiência e as minorias culturais (SANTOS, 2004; TORRES, 1996).

Muito embora o discurso sobre a necessidade de se enfatizar a educação básica, maior autonomia das escolas e envolvimento das famílias no processo educativo possam ser compreendidos como respostas a reivindicações dos setores da sociedade envolvidos com a educação, no âmbito das reformas educacionais implementadas nos anos de 1990 sob a orientação de organismos internacionais como o Banco Mundial, esse discurso assume outros sentidos, basicamente, o sentido da responsabilização da escola e dos sujeitos envolvidos no processo educativo pelos problemas aí enfrentados. Assim, o discurso reformista se apropria indevidamente de termos caros aos setores envolvidos com a educação para justificar as reformas implementadas.

Hypolito, Vieira e Pizzi (2009), baseados no estudo de Silva (1997), defendem que, no que diz respeito à formação docente, em primeiro lugar, pode-se esperar uma intervenção dos governos neoliberais para alterar diretamente os esquemas dessa formação, instituindo mecanismos de treinamento docente mais independentes das universidades e mais voltados para as necessidades técnicas e ideológicas do novo modelo de organização social e educacional. Essa nova orientação indica que os currículos e as abordagens desses esquemas de treinamento sejam predominantemente técnicos, gerenciais, práticos e pragmáticos, reproduzindo as preocupações

${ }^{1}$ Condições Gerais de Produção - O modo de produção capitalista, conforme defendido por Marx, pressupõe a transformação constante dos meios de produção e a renovação da técnica de produção, a fim de aumentar a parcela do trabalho excedente e, como consequência, a ocorrência da mais-valia. Com isso, há a possibilidade do aumento da produtividade e ampliação da realização do lucro por aumento de trabalho social não pago, ou seja, a ampliação da acumulação do capital. 
com eficácia e produtividade, tendo como consequência o distanciamento de campos e abordagens de inclinação mais política, social e cultural.

Há que se observar, no entanto, que muitas práticas de formação que atendem essas intencionalidades e mantém as características da racionalidade técnica vêm acompanhadas de um discurso de conveniência que afirma valorizar a reflexão, autonomia e a produção de conhecimento por meio da pesquisa dos professores.

Segundo Zeichner (2008), o termo "reflexão" acabou se tornando o slogan da reforma educacional e um dos usos mais comuns do conceito

[...] significou uma ajuda aos professores refletirem sobre seu ensino, tendo como principal objetivo reproduzir melhor um currículo ou um método de ensino que a pesquisa supostamente encontrou como mais efetivo para elevar os resultados dos estudantes nos testes padronizados. A pergunta que se faz aqui sobre a "reflexão" é a seguinte: Em que medida a minha prática está de acordo com aquilo que alguém deseja que eu faça? Em alguns casos, permite-se que o professor use sua criatividade para intervir em determinadas situações a fim de utilizar materiais e estratégias de ensino de uma maneira mais apropriada, mas isso geralmente não acontece (ZEICHNER, 2008, p. $541)$.

O autor chama a atenção para o fato de que a ideia de processo reflexivo está limitada à atividade técnica, isto é, à consideração das estratégias e habilidades de ensino, sendo que o professor está excluído da reflexão sobre os fins da educação.

Ainda conforme Hypolito, Vieira e Pizzi (2009), o processo de reestruturação educativa, o qual é parte constitutiva dos processos de reestruturação da sociedade, atinge diretamente a lógica de organização da educação e da escola. Segundo os autores, a passagem do controle público da educação e da escola, regido pela sociedade para o controle privado, diretamente regido pelo mercado, segundo os preceitos do neoliberalismo, provoca uma redução da autonomia relativa da educação em relação à economia. A escola passa a ser mais diretamente regulada pelas regras do mercado e da economia e sua organização cada vez mais é regida e avaliada por critérios técnicos de eficiência e produtividade.

A organização escolar compreende as condições objetivas sob as quais o ensino está estruturado, ou seja, envolve o currículo que se pratica em sala de aula, as metodologias de ensino e os processos de avaliação, por exemplo. As mudanças nessa organização provocadas pelas reformas educacionais dos anos 1990 alteram, também, a organização do trabalho docente nas escolas (OLIVEIRA, 2010). Assim, as reformas educacionais trouxeram novas exigências profissionais aos professores, porém, sem a adequação de suas condições de trabalho. Trouxeram, 
portanto, uma maior responsabilização do professor pelo desempenho dos estudantes e, também pela sua formação, obrigando-os a buscar constantemente, e por sua própria conta, formas de requalificação (OLIVEIRA et al., 2002).

Dessa forma, os professores passam a assumir muitas novas atribuições o que, muitas vezes, segundo Oliveira (2007, p. 3) os colocariam “[...] diante da necessidade de responder a exigências que estão para além de sua formação profissional". Os professores são cada vez mais obrigados a desempenharem funções de agente público, assistente social, enfermeiro, psicólogo, entre tantas outras, o que contribui para o sentimento de desprofissionalização, de perda de identidade profissional e da constatação que o ensinar, às vezes, não é o mais importante. Tal situação acaba sendo reforçada por estratégias de gestão que apelam ao comunitarismo e voluntariado, na perspectiva da promoção de uma educação para todos (OLIVEIRA, 2004).

Da mesma forma, é importante enfatizar que as mudanças ocasionadas pelas reformas educacionais trouxeram meios de padronização dos processos escolares, dos quais são exemplos os currículos centralizados, a adoção do livro didático, a implantação de programas de computadores, a realização sistemática dos exames nacionais de avaliação, evidenciando que a escola não é mais a mesma. Ainda,

[...] essa nova organização escolar reflete um modelo de regulação educativa, produto de novas articulações entre as demandas globais e as respostas locais. Por meio da descentralização administrativa, financeira e pedagógica, as escolas têm adquirido maior flexibilidade e autonomia, mas também têm respondido a uma demanda crescente de atividades e responsabilidades (OLIVEIRA, 2007, p. 356).

No que concerne à formação de professores no âmbito das reformas, é possível defender que esta sofreu significativas alterações, sendo que o contexto e as reformas neoliberais acabam por minimizar a importância da formação inicial do professor em detrimento de uma maior valorização das experiências de trabalho e de uma concepção individualizada de sucesso nas escolas (FERNANDES, 2008).

Mesmo a formação continuada é dificultada pelas mudanças empreendidas na organização escolar. As novas demandas que essas mudanças trazem somadas às condições de trabalho docente disponíveis em muitas escolas dificultam a efetivação da formação continuada centrada na escola, formação esta que, ocorrendo no contexto de trabalho, privilegia a colaboração, a interlocução entre as práticas, assim como as necessidades e os interesses dos professores, entendendo que os professores devem participar da construção da gestão do plano de formação da 
escola e constituírem-se como corresponsáveis pelo seu desenvolvimento (CUNHA; PRADO, 2010).

O que se observa, a partir das reformas, é uma formação docente voltada para o empirismo, na qual basta o professor saber aplicar adequadamente as orientações do sistema, deixando em segundo plano o exercício do pensamento e da abstração (FERNANDES, 2008).

A forma como as reformas educacionais alteraram a organização escolar e refletiram na formação continuada de professores é evidenciada nos enunciados das entrevistas das professoras e coordenadoras pedagógicas observados a seguir.

\section{A formação continuada e a organização escolar: análises da pesquisa}

A pesquisa foi desenvolvida no contexto de uma rede municipal de educação do interior do estado de São Paulo que conta com 46 escolas de ensino fundamental que atende aos anos iniciais, das quais 13 também atendem alunos da educação infantil. Embora não possa ser caracterizada como uma rede de ensino pequena, essa rede ainda não possui uma proposta pedagógica própria, elaborada pelo município, bem como um plano de cargos e carreira.

Foram entrevistadas oito professoras e quatro coordenadoras pedagógicas com o objetivo de analisar as ações de formaçãó ${ }^{2}$ continuada praticadas nessa rede.

As análises das transcrições das entrevistas, baseadas na análise de conteúdo (BARDIN, 2011), evidenciaram, entre outros aspectos, que a organização escolar vem sendo influenciada por orientações defendidas pelas reformas educacionais no que diz respeito ao currículo que se pratica em sala de aula, às metodologias de ensino e aos processos de avaliação. As professoras e coordenadoras pedagógicas afirmaram a centralidade que programas de formação continuada impostos pela secretaria da educação, como o Programa Ler e Escrever, assumiram no cotidiano das escolas da rede municipal modificando toda a sua organização.

O Programa Ler e Escrever foi elaborado em 2007 pelo Governo do Estado de São Paulo para sua rede de ensino como política pública para o Ciclo I que incluía formação, acompanhamento, elaboração e distribuição de materiais pedagógicos e outros subsídios para promoção da aprendizagem da leitura e escrita.

\footnotetext{
${ }^{2}$ A fim de manter o sigilo das professoras e coordenadoras entrevistadas, os nomes das participantes da pesquisa foram substituídos por nomes fictícios.
} 
Em 2009, por meio do Decreto 54.553/09 (SÃO PAULO, 2009a), o governo do Estado institui o Programa de Integração Estado/Município para o desenvolvimento de ações educacionais nas escolas das redes públicas municipais e com a Resolução SE 66 (SÃO PAULO, 2009b), a Secretaria de Estado da Educação estabelece convênio com a Fundação para o Desenvolvimento da Educação (FDE) e os municípios paulistas, tendo por objeto a implementação de programas e projetos, incluindo o Ler e Escrever.

Nesse contexto, o Programa Ler e Escrever foi implantado na rede pesquisada no ano de 2009 e a partir de então passou a ser o "carro chefe" desta instituição para o desenvolvimento do trabalho pedagógico nas escolas de ensino fundamental, determinando, consequentemente, as ações de formação continuada dos professores da rede.

Ressalta-se que o foco de atenção do artigo não é a proposta teórico-metodológica específica do Programa Ler e Escrever, ou seja, a discussão sobre o ensino da leitura e da escrita. Muitos autores já se dedicaram ao tema valorizando suas contribuições ou apontando limitações da proposta (ROSA, 2010; TASSONI; FERNANDES, 2015; SANTOS; TASSONI, 2015; DAVID; LOURENCETTI, 2015; BALBINO; FREIRE, 2018). A questão que interessa aqui é que esse programa, a partir de suas ações formativas, se configurou como uma política que alterou profundamente a organização escolar na rede analisada, colonizando os tempos de trabalho coletivo existentes no cotidiano das escolas. O Programa Ler e Escrever como referência de discussão é um exemplo de como as ações de formação continuada nas redes de ensino têm sido encaminhadas e como o processo reflexivo está subordinado à atividade técnica.

Na rede municipal investigada, o Ler e Escrever teve como marco inicial a formação de coordenadores pedagógicos, no segundo semestre do ano de 2009, a qual abarcava língua portuguesa e matemática. Posteriormente, somente a área de língua portuguesa passou a ser contemplada na formação semanal dos coordenadores. Essa formação tinha como objetivo instrumentalizar o coordenador pedagógico de modo que este profissional pudesse transmitir o conteúdo apreendido à equipe de professores sob sua responsabilidade, reforçando o que é defendido pelas reformas educacionais, ou seja, que o professor precisa desenvolver conhecimentos e competências para ensinar melhor.

O pressuposto dessa concepção de formação é que "[...] existe uma base de conhecimentos, verificada e estável, independente dos contextos, que deve ser transmitida ao 
professor para que ele desempenhe melhor a sua tarefa" (OLIVEIRA-FORMOSINHO, 2009, p. 228).

Esse modelo de formação orientado pela formação de um grupo de profissionais (coordenadores pedagógicos) que, como intermediários, vai replicar a formação para outro grupo de profissionais (professores), é conhecido como "modelo em cascata". Analisando esse procedimento, Gatti e Barreto (2009) ponderam que ele não tem contribuído com o aprofundamento dos princípios e estratégias de ensino propostos pelos próprios programas, entre outras razões porque o próprio corpo de formadores intermediários não está envolvido com sua concepção e desenvolvimento.

As entrevistas indicaram que as ações de formação docente promovidas pela rede de ensino tinham pouca sintonia com as necessidades e dificuldades das professoras e da escola, assim como a não participação dessas profissionais nas decisões acerca dos processos de formação aos quais são submetidas, da falta de conhecimento por parte dos formadores dos contextos escolares e dos professores que irão formar, entre outras, como é evidenciado na fala de uma das professoras:

[...] tem coisas que quem está trabalhando com a gente não tem noção do que é uma sala de aula; então, às vezes, coloca coisas para a gente que não dá para fazer numa sala de aula, por isso que eu acho que tinha que ouvir o professor. A Secretaria, para trabalhar, pôr um curso, ou as coordenadoras fazerem uma pesquisa, um levantamento com a gente primeiro, para levar lá, para aí ver que curso vai dar... Eu não sei como é decidido que curso é dado [...]. (Professora Adriana)

Como apontado por Oliveira-Formosinho (2009), a formação imposta aos professores de cima para baixo, do exterior para o interior, é percebida, muitas vezes, como desrespeito ou pouca valorização do conhecimento profissional prático do professor. Nesse sentido, o desenvolvimento é visto como “[...] algo que se faz ao professor e não algo que o professor faz em companhia” (p. 229).

A pesquisa confirma que o modelo de formação adotado pelo Programa Ler e Escrever, como de outras ações de formação continuada propostas pelas redes de ensino, estão baseadas no pressuposto do déficit, ou seja, pressupõe-se “[...] que os professores nada têm a dizer em termos do que é necessário para aprimorar sua formação e, por esse motivo, não há razão para consultá-los acerca do que precisam ou quanto ao que esperam para sua formação" (DAVIS et al., 2011, p. 86). 
Os excertos das entrevistas com as professoras confirmam essa percepção e neles é possível reconhecer a expectativa de que desejam participar da definição das propostas e planos de formação a elas endereçados:

[...] deveriam ouvir mais o professor que está na sala de aula. Eu acho que seria importantíssimo chegar na escola e fazer o levantamento: o que a gente precisa, o que é importante? Porque quem está ali com o aluno é o professor, que está ali direto, porque as coisas só vêm de cima para baixo. (Professora Adriana)

De repente falar assim: "Do que será que elas [professoras] estão precisando realmente? Do que essa escola precisa, do que aquela precisa, aquela região?". Porque é muito amplo. E, de repente, quem está [na gestão]... Quem será que propõe esses cursos? Eu não sei. Quem propõe aquela palestra dessa forma? Também não sei. Entendeu? Então, tem que ser quem está junto. (Professora Márcia)

Compreendeu-se, a partir das entrevistas, que tudo o que diz respeito à formação continuada é definido em outras instâncias e/ou por níveis hierárquicos superiores do sistema de ensino, uma vez que não se considera as especificidades dos professores e, também, de seus locais de trabalho. Neste sentido, baseando-se nas ideias defendidas por Davis et al. (2011), é possível destacar que as propostas de formação existentes na rede municipal de educação pesquisada tendem a ser uniformes, no formato "tamanho único" e "unissex", uma vez que o objetivo consiste em atingir o conjunto dos professores, independentemente de seu sexo, de sua idade, de seu tempo de experiência, de seus interesses etc.

Assim, o estudo apontou a ausência da prática de uma formação continuada centrada na escola, pois não se observou nas escolas participantes da pesquisa uma formação pautada na experiência profissional e pessoal das professoras, constituída como uma oportunidade de articulação dos interesses, necessidades e expectativas dos diversos sujeitos envolvidos no processo e no ato de reelaboração da profissão docente.

O enunciado da professora a seguir destaca esse aspecto:

[...] poderia ser levada mais em conta a escola, ter um pouco mais de autonomia para trabalhar aquilo que realmente a escola precisa. Como as coisas são muito fechadas pela Secretaria, vem tudo muito imposto, você acaba, então... A realidade realmente da sua sala, da sua escola, não é levada em conta. (Professora Antônia)

Pode-se afirmar que, conforme apontado pelas entrevistadas, as ações de formação realizadas nas escolas e propostas pela SME indicam uma formação verticalizada e centrada no sujeito professor e não no desenvolvimento de equipes pedagógicas.

Essa formação verticalizada parece servir para promover as mudanças na organização escolar, inserindo novos conteúdos, novos jeitos de ensinar e de avaliar, quase sempre com base 
no programa Ler e Escrever. Os professores percebem que as ações de formação parecem preparar para as mudanças que serão implantadas, determinando novos jeitos de fazer para o trabalho docente:

O que a gente observa é que, às vezes, vem como [...]alguma coisa que eles estão querendo implantar, ou que eles estão querendo que seja feita daquela forma. (Professora Fabiana)

Atrelada à perspectiva de treinamento para implementação de uma orientação específica vem o controle. Assim, as entrevistas apontaram a existência de um conjunto de exigências colocadas aos professores, bem como as expectativas que pesam sobre a sua atividade, a pressão em relação à verificação dos resultados imediatos da sua ação, principalmente por meio das avaliações externas.

Eu gosto da formação, eu gosto muito. A única coisa que me incomoda é que a Secretaria de Educação, hoje, aliou a formação à fiscalização, então, assim, a gente recebe uma formação que eu acredito que é para subsidiar o seu trabalho, mas, aí, a Secretaria enxerga que a formação que você recebe tem que ser seguida estritamente à risca. (Coordenadora Pedagógica Denise)

Isso nos permite observar que, a partir da proposta do Programa Ler e Escrever, os professores perderam grande parte de sua autonomia, tiveram que se adaptar aos métodos de ensino padronizados, se organizar diante da intensificação, da burocratização e da rotinização do seu trabalho. Embora afirme considerar o Programa em questão bom, uma das coordenadoras entrevistadas destaca a insuficiência dele para atender às necessidades das escolas:

Então, você tem um sistema que não é ruim, ele é bom, mas que nem sempre vai de encontro à necessidade do local onde a gente está trabalhando; então, eu acho que falta um pouquinho, nesse momento, autonomia para a gente trabalhar de forma diferenciada de acordo com o que a gente está vendo que é necessário naquele momento. (Coordenadora Pedagógica Rafaela)

A necessidade de adequar suas concepções e formas de ensinar ao conteúdo do Ler e Escrever denotam ainda um processo de intensificação do trabalho das professoras e das coordenadoras pedagógicas, acusado por meio do relato da existência de um aumento de tarefas e de responsabilidades, o que acaba gerando um sentimento de sobrecarga para essas profissionais.

Então, a gente tem que achar forças onde não tem, tirar de onde não tem, e, assim, a maior dificuldade é lidar com toda essa rotina nossa, esse tanto de coisas que é proposto. (Professora Márcia)

Igualmente, é possível observar que se encontra presente um processo de colonização do tempo dos docentes por meio das subjetividades e emoções que envolvem esses profissionais (GARCIA; ANADON, 2009). As entrevistadas relataram como seu tempo e espaço acabaram 
sendo ocupados pelas determinações externas com tarefas e atribuições motivadas pela ideia de produtividade e pelo controle, contribuindo para a intensificação desse trabalho:

[...] é a maior dificuldade: muitos projetos para serem atingidos, metas que não se consegue atingir, você queria fazer com maior tempo e não pode porque você tem prazo. Então, assim, isso é algo que me preocupa; então, eu às vezes não entendo, e até entendo, também. Eu até fico me perguntando: será que precisava de tudo isso? Será que... (Professora Márcia)

Com a constante presença do controle do trabalho docente, ocorre a dificuldade de as professoras pensarem o trabalho da escola por elas mesmas. Nesta perspectiva, é importante enfatizar que a crescente perda de autonomia, entendida como condição do professor de participar da concepção e organização do seu trabalho, acabou por ocasionar, da mesma maneira, um processo de desqualificação e desvalorização dos professores.

[...] a gente tem uma rotina extremamente desgastante. Então, muitas coisas, a gente acaba fazendo no automático. A gente acaba fazendo no automático, e, daí você deixa de refletir, isso é uma coisa que eu sempre falo para as minhas professoras e falo, também, nas nossas reuniões de formação: quando você tem uma rotina que é extremamente sobrecarregada, você deixa de refletir sobre algumas coisas, daí você faz para cumprir protocolo... então, eu tento manter um equilíbrio. Só que a gente sabe que é insuficiente, então, quando você começa a fazer as coisas automaticamente, é muito ruim. Então, se for pensar na minha própria formação, eu acho que eu não tenho todas as condições necessárias. (Coordenadora Pedagógica Denise)

Assim, parece que, em consonância com o que se discutiu antes aqui a respeito das mudanças provocadas na organização escolar por meio das reformas educacionais implementadas, a rede municipal de educação pesquisada parece promover, por meio da imposição de um novo currículo, de novos modos de ensinar e de avaliar, garantidos pela implementação do Ler e Escrever, formas de controle e de regulação do trabalho:

[...] então, a rede, hoje, quis padronizar todas as escolas, todo mundo tem que fazer a mesma coisa, e a gente perde um pouquinho de característica própria, a gente perde muito de autonomia, porque você não pode nem mudar o bimestre em que vai ser trabalhado determinado projeto, determinada sequência didática, mas, em termos de aquisição de conhecimento, eu gosto da formação, eu acho que ela é necessária. O que eu não tenho gostado ultimamente é dessa questão de não ter, mesmo, de a escola ter perdido completamente a autonomia e de não se considerar as características da comunidade local para planejar o próprio trabalho. Isso eu acho bem ruim. (Coordenadora Pedagógica Denise)

Neste sentido, compreende-se o quanto as professoras têm sido excluídas em seu trabalho junto aos alunos de planejar a partir de demandas específicas e coletivas, com autonomia, conhecimento e crítica no seu fazer pedagógico na escola.

As professoras e as coordenadoras pedagógicas sentem que não são ouvidas, que não podem expressar suas dúvidas e expectativas profissionais, pois a escola está organizada de modo 
a não possibilitar um ambiente de trabalho em que seja possível estabelecer laços sociocognitivos, afetivos e motivacionais dos professores com seus pares e que haja a possibilidade de uma abertura de novas ideias, concepções e caminhos alternativos.

\section{Considerações finais}

Este artigo apresentou resultados de pesquisa que buscou compreender como são desenvolvidas as ações de formação continuada nas escolas municipais de ensino fundamental de um município do interior paulista. Essas ações se dão em um contexto de uma organização escolar profundamente modificada pelas reformas educacionais implementadas a partir dos anos 1990.

As professoras e coordenadoras entrevistadas evidenciam que as ações de formação são determinadas de forma externa à escola visando adequar o que deve ser ensinado e a forma de se ensinar e avaliar às orientações decorrentes das reformas educacionais. Nesse sentido, o Programa Ler e Escrever é apontado pelas entrevistadas como elemento que modificou profundamente o trabalho realizado nas escolas à medida que padronizou as formas de ensinar e, também, induziu as ações de formação continuada praticadas.

É nesse sentido que as entrevistadas apontam que o modelo de formação realizado não considera as necessidades da escola, configurando-se como ações padronizadas para toda a rede municipal. Atrelada à padronização observa-se também o controle realizado por meio das avaliações. Assim, além de não serem ouvidos a respeito de suas necessidades formativas, os professores ainda são cobrados para implementar de forma satisfatória os conteúdos decorrentes da formação realizada pelo sistema de ensino.

Por fim, para dar conta das muitas demandas que decorrem dos novos modos de ensinar e avaliar preconizados por essas ações de formação, os professores têm seu trabalho intensificado, sendo submetidos ainda ao cumprimento de uma rotina na qual, muitas vezes, não veem sentido.

Os docentes almejam por respeito e interesse pelo seu trabalho por parte dos formadores e nos processos formativos dos quais participam, com vistas à melhoria da formação e aprendizagem dos alunos. 
GUARDA, Vanessa Moraes Abdala; BARBOSA, Andreza; CUNHA, Renata Cristina Oliveira Barrichelo. Mudanças na organização escolar e formação docente continuada em um município do interior paulista.

\section{Referências}

BALBINO, K. T. S.; FREIRE, R. M. A. C. O Programa Ler e Escrever e o ensino e aprendizagem da leitura e escrita: estudo de caso. Revista e-Curriculum, São Paulo, v. 16, n. 2, p. 539-564, abr./jun. 2018.

BARDIN, L. Análise de conteúdo. Lisboa: Edições 70, 2011.

CUNHA, M. I. O tema da formação de professores: trajetórias e tendências do campo na pesquisa e na ação. Educação e Pesquisa, São Paulo, v. 39, n. 3, p. 609-625, jul./set. 2013.

CUNHA, R. C. O. B.; PRADO, G. V. T. Formação centrada na escola, desenvolvimento pessoal e profissional de professores. Revista de Educação PUC-Campinas, Campinas, n. 28, p.101-111, jan./jun. 2010.

DAVID, A.; LOURENCETTI, G. C. A política educacional paulista: o Programa Ler e Escrever. Comunicações, Piracicaba, v. 22, n. 1, p. 53-64, jan./jun. 2015.

DAVIS, C. L. F. et al. Formação continuada de professores: uma análise das modalidades e das práticas em estados e municípios brasileiros. Estudos \& Pesquisas Educacionais, São Paulo, v. 34, n. 2, p. 81166, nov. 2011.

FERNANDES, M. J. S. A coordenação pedagógica em face das reformas escolares paulistas (19962007). 2008. Tese. (Doutorado em Educação Escolar) - Faculdade de Ciências e Letras, Universidade Estadual Paulista, Araraquara, 2008.

GARCIA, M. M. A.; ANADON, S. B. Reforma educacional, intensificação e autointensificação do trabalho docente. Educação \& Sociedade, Campinas, v. 30, n. 106, p.63-85, jan./abr. 2009.

GATTI, B. A.; BARRETO, E. A. S. A. (Coord.). Professores do Brasil: impasses e desafios. Brasília: UNESCO, 2009.

HYPOLITO, A. M.; VIEIRA, J. S.; PIZZI, L. C. V. Reestruturação e curricular e auto-intensificação do trabalho docente. Currículo sem Fronteiras, Brasil, v. 9, n. 2, p. 100-112, jul./dez. 2009.

IMBERNÓN, F. Formação permanente do professorado: novas tendências. São Paulo: Cortez, 2009.

MARX, K. O Capital: crítica da economia política. O processo de produção do capital. São Paulo: Bointempo, 2013. Livro I.

OLIVEIRA, D. A. Mudanças na organização e na gestão do trabalho na escola. In: OLIVEIRA, D. A.; ROSAR, M. F. F. (org.). Política e gestão da educação. 3. ed. Belo Horizonte: Autêntica, 2010. p. 127145.

OLIVEIRA, D. A. Trabalho docente e qualidade da educação: tradições e contradições. In: SIMPÓSIO BRASILEIRO DE POLÍTICA E ADMINISTRAÇÃO DA EDUCAÇÃO, 23., 2007. Porto Alegre. Anais [...]. Porto Alegre: UFRGS, 2007. p. 1-16.

OLIVEIRA, D. A. A reestruturação do trabalho docente: precarização e flexibilização. Revista Educação e Sociedade, Campinas, v. 25, n. 89, p. 1127-1144, set./dez. 2004.

OLIVEIRA, D. A. et al. Transformações na organização do processo de trabalho docente e suas consequências para os professores. Trabalho e Educação, Belo Horizonte, v. 11, p. 51-65, jul./dez. 2002.

OLIVEIRA-FORMOSINHO, J. Desenvolvimento profissional dos professores. In: FORMOSINHO. J. (coord.). Formação de professores: aprendizagem profissional e acção docente. Porto: Porto Editora: 2009. p. 221-284. 
ROSA, S. S. A relação dos professores com o saber em uma proposta curricular padronizada de alfabetização: reflexões sobre o "Programa Ler e Escrever". Revista e-Curriculum, São Paulo, v. 5, n. 2, p. 2-17, jul. 2010.

SANTOS, L. L. C. P. Formação de professores na cultura do desempenho. Educação e Sociedade, Campinas, v. 25, n. 89, p. 1145-1157, set./dez. 2004.

SANTOS, T. C.; TASSONI, E. C. M. As práticas pedagógicas e o material didático do Programa Ler e Escrever no $1^{\circ}$ ano do ensino fundamental. Revista Brasileira de Estudos Pedagógicos, Brasília, v. 96, n. 242, p. 79-95, jan./abr. 2015.

SÃO PAULO. Decreto n. 54.553, de 15 de julho de 2009. Institui o Programa de Integração Estado/Município para o desenvolvimento de ações educacionais nas escolas das redes públicas municipais, autorizando a Secretaria da Educação a representar o Estado de São Paulo na celebração de convênios com a Fundação para o Desenvolvimento da Educação - FDE e municípios paulistas. São Paulo: Governo do Estado de São Paulo, 2009a. Disponível em: https://governosp.jusbrasil.com.br/legislacao/818036/decreto-54553-09. Acesso em: 9 set. 2018.

SÃO PAULO. Secretaria da Educação. Resolução SE n. 66, de 2 de agosto de 2009. Dispõe sobre a implementação do disposto no Decreto ${ }^{\circ} 54.553$, de 15 de julho de 2009, que institui o Programa de Integração Estado/Município para o desenvolvimento de ações educacionais conjuntas que proporcionem melhoria da qualidade da educação nas escolas das redes públicas municipais. São Paulo: Governo do Estado de São Paulo, 2009b. Disponível em: http://lereescrever.fde.sp.gov.br/Handler/UplConteudo.ashx?jkasdkasdk=145\&OT=O. Acesso em: 9 set. 2018.

SILVA, T. T. Educação Pós-Crítica e formação docente. Cadernos de Educaçãa, Pelotas, n. 8, p. 155170, jun. 1997.

TASSONI, E. C. M.; FERNANDES, J. O Programa Ler e Escrever: uma experiência no $4^{\circ}$ e no $5^{\circ}$ ano. Revista Educação PUC Campinas, Campinas, v. 20, n. 1, p. 3-26, jan./abr. 2015

TORRES, R. M. Melhorar a qualidade da educação básica? As estratégias do Banco Mundial. In: TOMMASI, L. et al. O Banco Mundial e as políticas educacionais. São Paulo: Cortez, 1996. p. 125179.

ZEICHNER, K. M. Uma análise crítica sobre a "reflexão" como conceito estruturante na formação docente. Educação e Sociedade, Campinas, v. 29, n. 103, p. 535-554, maio/ago. 2008. 